\title{
Financial Distress among Advanced Cancer Patients assessed in a Supportive Care Outpatient Center.
}

\author{
Marvin Omar Delgado Guay, Maxine G. De la Cruz, Janet Williams, Eduardo Bruera \\ The University of Texas MD Anderson Cancer Center \\ Department of Palliative Care, Rehabilitation and Integrative Medicine
}

Background: Advanced cancer patients(AdCa) experience physical, psychological, existential/spiritual distress and financial distress(FD) associated with the disease or treatment. Regular assessments of these issues in the outpatient-setting are limited.

Methods: We reviewed 289 consults of AdCa evaluated by our Supportive Care Outpatient-Center between October2012 and January-2013. We used Edmonton Symptom Assessment Scale adding two items following the same scale $(0$ to 10) to evaluate: Spiritual Pain and FD, (ESAS-FS). We determined the frequency, intensity and correlates of selfreported FD (Distress/Suffering experienced secondary to financial issues) among these AdCa.

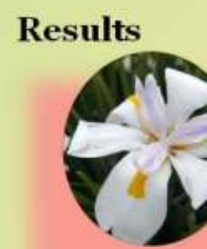

Mean age(range): 60.1 years(22-92). 53\% were male. $189(65 \%)$ were White, $45(15 \%)$ African American, and 34(12\%) were Hispanic.

Type of cancer: head and neck 62(21\%), gastrointestinal 57(20\%), breast 40(14\%), lung $32(11 \%)$, urological 32(11\%), and others $45(16 \%)$.

187/289(65\%) AdCa had FD: mean(95\% Confidence-Interval) 4(3.5-4.4). AdCa with FD had worse Pain [mean $(95 \% \mathrm{CI}) 5.12(4.7,5.6)$ vs. $4.3(3.6,4.9)](\mathrm{p}=0.028)$, depression $[3.8(3.3,4.2)$ vs. $1.5(1.1,2.1), \mathrm{p}<0.0001]$, anxiety [4.1(3.6, 4.6 vs. 1.6(1.1, 2.1), $\mathrm{p}<0.0001]$, Well-Being [5.2 (4.9, 5.6) vs. $4.3(3.7,4.9), \mathrm{p}=0.006]$, and Spiritual Pain[2.4(2.0, 2.9) vs. $0.5(0,1.0), \mathrm{p}<0.0001]$.

FD correlated (Spearman) with Pain $\mathrm{r}=0.25, \mathrm{p}<0.0001$; Sleep $\mathrm{r}=0.29, \mathrm{p}<0.0001$; Depression $r=0.41, p<0.0001$; Anxiety $r=0.45, p<0.0001$; Drowsiness $r=0.26, p<0.0001$, Well-being $\mathrm{r}=0.25, \mathrm{p}<0.0001$; and Spiritual Pain $\mathrm{r}=0.44, \mathrm{p}<0.0001$.

Logistic regression multivariate analysis showed association with Spiritual Pain[OR $(95 \%$ Wald CI) 1.575(1.284-1.932), $\mathrm{p}<0.0001]$ and Anxiety [1.261 (1.083-1.488), $\mathrm{p}<0.0001]$.

\section{Conclusion:}

FD was reported in more than $65 \%$ of AdCa. It correlates with physical and psychological, and spiritual distress. The use of ESAS-FS allows identifying AdCa with FD evaluated in a Supportive Care Outpatient Clinic. More research is needed. 